\title{
Monitoring the Shelf-Life of Minimally Processed Fresh-Cut Apple Slices By Physical - Chemical Analysis and Electronic Nose
}

\author{
Valeria Guarrasi $^{1^{*}}$, Daniela Giacomazza ${ }^{1}$, Maria Antonietta Germanà ${ }^{2}$, Margherita Amenta $^{3}$, Pier Luigi San Biagio ${ }^{1}$ \\ ${ }^{1}$ Istituto di Biofisica, Consiglio Nazionale delle Ricerche, Via Ugo La Malfa 153, 90146 Palermo, Italy \\ ${ }^{2}$ SAF Department, University of Palermo, Viale delle Scienze 4, 90128 Palermo, Italy \\ ${ }^{3}$ CRA - Centro di Ricerca per l'Agrumicoltura e le Colture Mediterranee, Corso Savoia 190, 95024 Acireale (CT), Italy
}

*Corresponding author: Valeria Guarrasi, Istituto di Biofisica, Consiglio Nazionale delle Ricerche, Via Ugo La Malfa, 153,90146 Palermo (Italy), Phone: +390916809356; Fax: +390916809312; E-mail: valeria.guarrasi@pa.ibf.cnr.it

Received date: June 11, 2014, Accepted date: July 25, 2014, Published date: July 27, 2014

Copyright: @ 2014 Guarrasi V, et al. This is an open-access article distributed under the terms of the Creative Commons Attribution License, which permits unrestricted use, distribution, and reproduction in any medium, provided the original author and source are credited.

\begin{abstract}
Fresh-cut apples, in slices or in cubes, are minimally processed products, which are currently collecting a great interest by fruit marketers for their promising diffusion. Their shelf life, from a microbiological point of view, has been fixed about 2 or 3 weeks under refrigeration. However in a few days they undergo biochemical degradations with production of off-flavors and texture breakdown. In this work, the change of aromatic fingerprint of apple slices packaged in air and in a modified atmosphere (with $100 \% \mathrm{~N}_{2}$ ) and stored at $4^{\circ} \mathrm{C}$ was measured, by using a commercial electronic nose. The obtained data were also compared with sensory evaluation of judge's panel. Moreover, quality parameters such as total acidity, total soluble solids and firmness were determined at different storage times $(0,4,8$ and 12 days).
\end{abstract}

The data show that the electronic nose is able to discriminate between the two different storage conditions applied: the multivariate analysis, Principal Component Analysis, presents clearly differences among the four sampling times when the apple slices are stored in air and in $\mathrm{N}_{2}$.

Our results indicate that the electronic nose can be considered a valid supplementary tool to human sensory panel assessment especially in food quality safety and control and it can be a simple, objective and rapid method to control the food quality during the storage.

Keywords: Fresh-cut apples; Shelf-life; Electronic nose; Sensory analysis; Food storage; Minimally processed fruit

\section{Introduction}

Recently the demand for minimally processed fruits and vegetables is increasing. The ready-to-eat fresh-cut products are one of the major growing segments in food markets. The rapid growth is due to the new lifestyles and to the health-consciousness of the consumers [1]. In fact, they request fresh-like processed products with high quality attributes (such as appearance, texture, and flavor) similar to those of the raw products [2] to satisfy the daily needs of antioxidants, minerals and dietary fibers. The ready-to-eat fresh-cut products are slightly processed products, retaining intact the positive characteristics of the fresh fruits and vegetables. Minimal processing has been defined as a combination of procedures, such as washing, peeling, slicing or chopping, not affecting the fresh-like quality and flavor of the food [3]. However, fresh-cut fruits are more challenging to obtain than other processed products for the difficulties in preserving their fresh-like properties during prolonged periods. The tissue integrity of fruits, in fact, can be easily altered during the shelf-life time [4-6].

Fresh-cut apples, in slices or in cubes, are lightly processed products and the fruit marketers have shown a great interest in their development. Although from a microbiological point of view, their shelf-life, in refrigerated conditions, has been fixed to 2 or 3 weeks [7], biochemical degradations, such as enzymatic browning, off-flavors release and texture breakdown, occur in a few days [8]. The addition of chemical additives (preservatives, antioxidants, edible coating, colorants, etc.), although used to prolong the shelf-life [9-11] can be associated with health problems such as allergies and more [12]. On this basis, new techniques to maintain the natural qualities of readyto-eat fruits without using chemical preservatives were developed. The Nicoli's group first proposed the use of a modified atmosphere composed by $80 \% \mathrm{~N}_{2}$ and $20 \% \mathrm{CO}_{2}$ to better preserve the apple slice quality [13]. Ever since, many attemps have been done to identify the better atmosphere composition to preserve the fresh fruit quality $[14,15]$.

The fruit quality is not a single and well-defined attribute but comprises many properties or characteristics. In many cases, indicators of fruit maturity, such as color, total soluble solids and titratable acids, may not be sufficient to determine optimal sensory quality [16].

Aroma is one of the most important quality parameter perceived by consumers. Gas chromatography technique is usually employed to identify the fruit aroma, while sensory analysis is used to assess the intensity of the aroma descriptors [17]. Whether the chromatographic techniques require special equipment and dedicated staff, the sensory analysis also presents some drawbacks, such as the duration of the panel training and, sometimes, the dubious objectivity of the results. New technologies have been tested on fruits, aiming for fast and, in some cases, non-destructive volatile detection $[18,19]$. The electronic 
Page 2 of 4

olfactory systems or electronic noses are the new technologies that can be used to predict fruit quality [20-23].

In this work we studied the changes of aromatic fingerprint of apple slices, packaged in atmospheric air and in a modified atmosphere $\left(100 \% \mathrm{~N}_{2}\right)$, stored at $4^{\circ} \mathrm{C}$, for $0,4,8$ and 12 days by an electronic nose. A commercial type of electronic nose, $\mathrm{EOS}^{835}$, based on metal oxide semiconductor sensors (MOS), to detect changes in volatile profiles due to storage conditions and during shelf life was used. Moreover, classical quality parameters, such as total acidity, total soluble solids, firmness and sensory profile by trained judges, were also determined.

\section{Materials and Methods}

\section{Apples and fruit processing}

'Fuji' apples were harvested on September 2009 in Caltavuturo (Palermo, Italy) in an organic farm. Thirty fruits were selected for regular shape, uniform size and same ripeness stage. The fruits were cleaned with distilled water, dried and cut into slices of $1 \mathrm{~cm}$ thickness. The slices were individually put in the plastic bags $(10 \times 10 \mathrm{~cm})$ and no pre-processing coating was applied. The bags were heat-sealed in atmospheric air (Air) and in nitrogen saturated $\left(\mathrm{N}_{2}\right)$ atmosphere. The plastic bags, purchased from Reber (Italy), presented a permeability to $\mathrm{O}_{2}$ of $70.5 \mathrm{~cm}^{3} /\left(\mathrm{m}^{2} 24 \mathrm{~h} \mathrm{~atm}\right)$ at the temperature of $23^{\circ} \mathrm{C}$ and $0 \%$ relative humidity and to $\mathrm{N}_{2}$ of $10.5 \mathrm{~cm}^{3} /\left(\mathrm{m}^{2} 24 \mathrm{~h}\right.$ atm $)$ at the same temperature and relative humidity. All the sealed bags were stored in refrigerator at $4 \pm 1^{\circ} \mathrm{C}$ in darkness. The samples were analyzed just before packaging ( 0 day) and after 4,8 and 12 storage days. At each chosen time, 10 packages for trial (Air and $\mathrm{N}_{2}$ ) were randomly taken to perform the analysis.

\section{Physical and chemical analyses}

The juice soluble solid content (SSC) was determined by an optical refractometer (Atago Co., Ltd., Japan); results are expressed as ${ }^{\circ}$ Brix.

Total acidity (TA) was measured by titration with $0.1 \mathrm{~N} \mathrm{NaOH}$. Three replicates were performed and the results expressed as $\mathrm{g} / \mathrm{L}$ of citric acid.

Firmness measurements were performed by EFFEGI Texture Analyzer by determining the maximum force during the penetration of a $8 \mathrm{~mm}$ diameter stainless steel cylinder into the apple slice tissue. Results were expressed as kgf.

Statistical analysis was carried out using the STATSOFT 6.0 program (Vigonza, Padova, Italy). The statistical differences among different storage times were evaluated by variance analysis (ANOVA), and mean separation was performed by using the Tukey's test.

\section{Sensory evaluation}

A judge's panel was engaged in the sensory analysis. The judges (10 persons) were trained in some preliminary sessions by using different apple samples, in order to develop a common vocabulary for the description of the sensorial attributes. Eight descriptors were chosen to describe the quality of apple's slices: appearance, browning, flavor, consistency, juiciness, sweetness, acidity, and pleasantness. Samples were evaluated by assigning a score between 1 (absence of the sensation) and 5 (extremely intense), except for the descriptor 'browning' where a reverse evaluation ( $1=$ maximum; $5=$ minimum) was adopted. Water at room temperature was used to rinse the sample before tasting. No statistical analysis of the data was carried out.

\section{Electronic Nose measurements}

An $\operatorname{EOS}^{835}$ (Sacmi, Italy) was used to detect the aromatic fingerprint at different storage times. The $\operatorname{EOS}^{835}$ instrument, belonging to the so-called "electronic noses", consists of an array of metallic oxide semiconductor (MOS) resistances installed inside a patented measuring cell, the "sensors chamber". The interaction with odor molecules causes variation of the electrical conductivity. The MOS sensors are doped with different metallic oxides (Table 1) that react differently to the same odorous molecules, thus generating a set of signals (olfactory imprint or aromatic fingerprint) characteristic of each analyzed sample. All measurements were done in triplicate, cutting $3 \mathrm{~g}$ of slices and placing them into $20 \mathrm{ml}$ vials. Each vial was sealed and conditioned at $40^{\circ} \mathrm{C}$ for 10 minutes before analysis to ensure that the aroma reached the vial headspace. After equilibration, $4 \mathrm{ml}$ of headspace was drawn in. The interaction between flavors and sensor layers causes a modification of the sensor resistance. A typical measurement profile is given in Figure 1. After each measurement the sensors are constantly purged with GC-grade air. The difference between the resistance value at rest, $\mathrm{R}_{0}$, and that one induced by sample volatile compounds, $\mathrm{R}$, is considered as the sensor response. After each measurement, the electronic nose chamber is flushed again with pure grade air. The measurement duration was 16 minutes (1 min of cleaning before, $2 \mathrm{~min}$ of measurement, $13 \mathrm{~min}$ of clearing after). Six values, $\left\{R_{S 1}, \ldots, R_{S 6}\right\}$, corresponding to the six different sensors, were obtained for each measurement and data pre-processing was carried out. The feature Delta was obtained from the sensor response curve (Figure 1). Principal Component Analysis (PCA) was used as unsupervised statistic method to reduce the dimensional space and plot the data, by a correlation matrix. PCA transforms the original variables into new uncorrelated ones called "principal components". The first component (PC1) describes the larger amount of the data. The second principal component (PC2) is orthogonal to the first one and covers almost the whole remaining variation and so on (PC3... PC6).

\begin{tabular}{|l|l|l|l|}
\hline Sensor No. & Sensor Code & Sensitive Layer & Temperature \\
\hline $\mathbf{1}$ & $\mathrm{CJ} 1316$ & $\mathrm{SnO}_{2}$ cat $\mathrm{SiO}_{2}$ & $450^{\circ} \mathrm{C}$ \\
\hline $\mathbf{2}$ & $\mathrm{SB} 0225$ & $\mathrm{SnO}_{2}$ cat $\mathrm{Ag}$ & $400^{\circ} \mathrm{C}$ \\
\hline $\mathbf{3}$ & $\mathrm{SD} 0515$ & $\mathrm{SnO}_{2}$ cat $\mathrm{Mo}$ & $400^{\circ} \mathrm{C}$ \\
\hline $\mathbf{4}$ & $\mathrm{SH} 0612$ & $\mathrm{WO}_{3}$ & $375^{\circ} \mathrm{C}$ \\
\hline $\mathbf{5}$ & $\mathrm{SJ} 0717$ & $\mathrm{SnO}_{2}$ & $450^{\circ} \mathrm{C}$ \\
\hline $\mathbf{6}$ & WHT19 & $\mathrm{WO}_{3}$ & $400^{\circ} \mathrm{C}$ \\
\hline
\end{tabular}

Table I: MOS sensor array configuration of the $\operatorname{EOS}^{835}$.

\section{Results and Discussion}

\section{Physical and chemical parameters}

The physical and chemical characteristics of apples processed in Air and in $\mathrm{N}_{2}$ and stored for $0,4,8$ and 12 days are reported in Table 2. The SSC and TA values do not show noteworthy changes as function of the storage time both in Air and in $\mathrm{N}_{2}$. 
Penetration measurements performed in both experimental condition (air and $\mathrm{N}_{2}$ ) showed significant differences in the apple texture, especially in the sample packaged in Air $(p \leq 0.001)$. In the case of apple slices packaged in $\mathrm{N}_{2}$ the $\mathrm{p}$ value calculated for firmness modifications was $\mathrm{p} \leq 0.05$. After 12 days the texture of slices stored in Air was softer than that one of samples stored in $\mathrm{N}_{2}$, thus indicating that a modified atmosphere was more able to save the sample hardness $[24,25]$. The maintenance of the texture is considered a positive attribute in processed apples.

\section{Sensory evaluation}

Results concerning sensory analysis are shown in the radar plot for the 8 chosen descriptors (Figures $2 \mathrm{a}$ and b). 'Sweetness', 'acidity' and 'consistency' are in agreement with analytical data results. Figure $2 \mathrm{a}$ illustrates that the scores of global 'appearance' for apple slices stored in Air after 8 and 12 days were the same, probably due to the presence of brown and soft parts that influenced the acceptance of the judges. Samples stored in $\mathrm{N}_{2}$ (Figure $2 \mathrm{~b}$ ) showed the lowest 'appearance' score after 12-day packing time. The 'flavor' descriptor behavior is different for apple slices stored in Air and in $\mathrm{N}_{2}$ : the same value was attributed to samples packaged in Air for $0-4$ days and smaller value was assigned to samples examined after $8-12$ days. In the $\mathrm{N}_{2}$ case, the same values were attributed to apples packaged for $0,4,8$ days and smaller value for those saved for 12 days.

\section{Electronic Nose data}

A PCA correlation matrix was carried out on the electronic nose data (Figure 3). For the apple slices packaged in air, the two first principal components, $\mathrm{PC} 1$ and $\mathrm{PC} 2$, accounted for $94.07 \%$ of the total variance $(73.92 \%$ and $20.15 \%$ respectively) (Figure $3 a)$. Samples were distributed along PC1 according to the storage time. The aroma showed changes from 0 to 12 days of storage. At 0 and 4 days, as well as at 8 and 12 days, the aromatic fingerprint is in agreement with the panel estimation.

In the case of apple slices packaged in nitrogen, the two first principal components, $\mathrm{PC} 1$ and $\mathrm{PC} 2$, accounted for $94.60 \%$ of the total variance $(75.88 \%$ and $18.72 \%$ respectively) (Figure $3 \mathrm{~b}$ ). Also in this set, samples were distributed along PC1 according to the storage time. The behavior of aromatic fingerprint was different from that observed for samples packaged in air. In fact, data suggest that the aroma is better preserved in nitrogen: the aroma of samples stored for 0,4 , and 8 days in $\mathrm{N} 2$ was separated in a cluster independent on that obtained in the case of samples stored for 12 days. Also in this case the electronic nose response was similar to value assigned by the panel.

Furthermore, the electronic nose results confirm data previously obtained by penetration measurements: the aroma changes are consequence of firmness loss.

\section{Conclusions}

Fresh-cut apple tissues undergoing changes during storage, including production of compounds affecting the fruit flavor. Our data show that changes of the aroma fingerprint detected by electronic nose measurements are in agreement with results obtained by physicalchemical analysis and human evaluation panel.

Furthermore, product storage in modified atmosphere $\left(\mathrm{N}_{2}\right)$ is able to prolong the shelf-life of the fresh-cut apple slices up to 1 week.
The approach here used can be applied to evaluate the loss of aroma quality of other fresh-cut products, in which enzymatic and microbiological processes are responsible for the decrease of the shelf life.

\section{Acknowledgements}

The Authors would like to thank Dr. Laura Dollo for technical support and useful discussions.

\section{References}

1. Michaelidou N, Hassa LM (2007) The role of health consciousness, food safety concern and ethical identity on attitudes and intentions towards organic food. Int J Consumer Studies 32: 163-170.

2. Wong DWS, Tillin SJ, Hudson JS, Pavlath AE (1994) Gas exchange in cut apples with bilayer coatings. J Agric Food Chem 42: 2278-2285.

3. Odriozola-Serrano I, Soliva-Fortuny R, Mantìn-Belloso O (2008) Effect of minimal processing on bioactive compounds and color attributes of fresh-cut tomatoes. LWT - Food Science and Technology 41: 217-226.

4. Rolle RS, Chism GW (1987) Physiological consequences of minimally processed fruits and vegetables. J Food Qual 10: 157-177.

5. Rosen JC, Kader AA (2008) Postharvest Physiology and Quality Maintenance of Sliced Pear and Strawberry Fruits. J Food Sci 54: 656-659.

6. Catalano AE, Sapienza M, Peluso O, Spagna G (2008) Miglioramento qualitativo degli ortofrutticoli di IV Gamma: ruolo dei principali enzimi degradativi. Industrie alimentari - XLVII: 479-485.

7. Garcia E, Barret DM (2002) Preservative treatments for fresh-cut fruits and vegetables. In: Lamikanra $\mathrm{O}$ (ed) Fresh-cut fruits and vegetables. CRC Press, Boca Raton, FL (USA).

8. Barry-Ryan C, Martìn-Diana AB, Rico D, Barat JM (2007) Extending and measuring the quality of fresh-cut fruit and vegetables: a review. Trends in Food Sci Technol 18: 373-386.

9. Ahvenainen R (1996) New approaches in improving the shelf life of minimally processed fruit and vegetables. Trends in Food Science \& Technology 7: 179-187.

10. Soliva-Fortuny RC, Marti'n-Belloso O (2003) New advances in extending the shelf-life of fresh-cut fruits: a review. Trends in Food Science \& Technology 14: 341-353.

11. Chien PJ, Sheu F, Yang SH (2007) Effects of edible chitosan coating on quality and shelf life of sliced mango fruit. Journal of Food Engineering 78: 225-229.

12. Halliwell B Murcia MA, Chirico S, Aruoma OI (1995) Free radicals and antioxidants in food and in vivo: what they do and how they work. See comment in PubMed Commons below Crit Rev Food Sci Nutr 35: 7-20.

13. Nicoli MC, Anese M, Severini C (1994) Combined effects in preventing browning reactions in minimally processed fruit. J Food Qual 17: 221-229.

14. Viskelis P, Rubinskiene M, Sasnaukas A, Bobinas C, Kvkliene N (2011) Changes in apple fruit quality during a modified atmoshere storage. Journal of Fruit and Ornamental Plant Research 19: 155-165.

15. Rocha AMCN, Barreiro MG, Morais AMMB (2004) Modified atmosphere package for apple "Bravo de Esmolfe". Food Control 15: 61-64.

16. Mehinagic E, Royer G, Symoneaux R, Jourjon F, Prost C (2006) Characterization of odor-active volatiles in apples: influence of cultivars and maturity stage. See comment in PubMed Commons below J Agric Food Chem 54: 2678-2687.

17. Defilippi BG, San Juan W, Valdés H, Moya-León MA, Infante R, et al. (2009) The aroma development during storage of Castlebrite apricots as evaluated by gas chromatography, electronic nose, and sensory analysis. Postharvest Biology and Technology 51: 212-219.

18. Nicolaï BM Defraeye T, De Ketelaere B, Herremans E, Hertog ML, et al. (2014) Nondestructive measurement of fruit and vegetable quality. See 
Citation: Guarrasi V, Giacomazza D, Germanà MA, Amenta M, Biagio PLS (2014) Monitoring the Shelf-Life of Minimally Processed Fresh-Cut Apple Slices By Physical - Chemical Analysis and Electronic Nose. Agrotechnol 3: 1000126. doi:10.4172/2168-9881.1000126

Page 4 of 4

comment in PubMed Commons below Annu Rev Food Sci Technol 5: 285-312.

19. Baldwin EA Bai J, Plotto A, Dea S (2011) Electronic noses and tongues: applications for the food and pharmaceutical industries. See comment in PubMed Commons below Sensors (Basel) 11: 4744-4766.

20. Falasconi M, Concina I, Sberveglieri V, Pulvirenti A, Sberveglieri G (2012) Electronic nose for the microbiological quality control of food products. Int J Electrochemistry 2012: 715763.

21. Lebrun M, Plotto A, Goodner K, Ducamp MN, Baldwin EA (2008) Discrimination of mango fruit maturity by volatiles using the electronic nose and gas chromatography. Postharvest Biology and Technology 48: $122-131$.

22. Concina I, Falasconi M, Sberveglieri V (2012) Electronic Noses as Flexible Tools to Assess Food Quality and Safety: Should we Trust Them? IEEE Sensors Journal 12: 3232-3237.
23. Garcia-Breijo E, Guarrasi V, Masot Peris R, Alcañiz Fillol M, Pinatti CO (2013) Odour sampling system with modifiable parameters applied to fruit classification. Journal of Food Engineering 116: 277-285.

24. Keenan DF, Valverde J, Gormley R, Butler F, Brunton NP (2012) Selecting apple cultivars for use in ready-to-eat desserts based on multivariate analyses of physico-chemical properties. LWT - Food Science and Technology 48: 308-315.

25. Portela SI, Cantwell MI (1998) Quality changes of minimally processed honeydew melons stored in air or controlled atmosphere. Postharvest Biology and Technology 14: 351-357. 